\title{
Bitumen: a challenge for toxicology and occupational health
}

\author{
Gerhard Schlüter
}

Received: 7 January 2011 / Accepted: 10 February 2011 / Published online: 25 February 2011

(C) Springer-Verlag 2011

Setting of occupational exposure limits (OEL) for bitumen is currently on the agenda of regulatory bodies internationally. Bitumen is mainly used in paving and roofing applications. Its chemical composition is variable and depends on the composition of the underlying crude oil and the manufacturing process. Bitumen consists mainly of aliphatic compounds, aromatic hydrocarbons, heterocyclic compounds containing nitrogen, oxygen, and sulfur atoms, and small amounts of polycyclic aromatic hydrocarbons (PAH). Depending on the type of bitumen and its laying temperature, workers are exposed to different quantities of various bitumen constituents, with varying concentrations of vapors and aerosols. The complex composition is one of the reasons why investigations, which may serve as a basis for occupational standard setting, are scarce. Another reason is the difficulty to organize field studies with a sufficiently large number of exposed persons, when the working places and associated working conditions are highly variable. Therefore, investigations into the health effects of occupational bitumen exposure have been remained a major scientific challenge.

Bitumen for long has been regarded as possible carcinogen because of its contents of polycyclic aromatic hydrocarbons (PAH). For instance, the German MAK commission had classified bitumen as a suspected carcinogen (K3) already in the 1980s, and a health-based OEL was not derived (Greim 2001). Instead, the German tripartide Committee for Hazardous Substances (AGS) had set a TRK value (Technical Guidance Concentration), which reflects the technically manageable exposure.

G. Schlüter ( $\square)$

Wuppertal, Germany

e-mail: gerhard.schlueterGS1@gmx.net
A classification of bitumen as carcinogenic was seemingly confirmed by positive carcinogenicity results of a long-term bioassay using dermal application (Sivak et al. 1997). In Germany, these findings led to lowering of the TRK value, which was finally suspended by end of 2004 .

Industry, however, argued that the route of administration in the dermal bioassay did not reflect the occupational exposure. Therefore, new studies were initiated to further clarify the situation. A long-term inhalation carcinogenicity study in rats turned out to be negative (Fuhst et al. 2007), and substantial efforts were made to gain sustainable data on human health from exposed persons. Missing data on possible respiratory effects were of particular interest. So far, only few studies have characterized the effects of bitumen exposure on nonmalignant responses of the respiratory tract, and especially data on irritative effects of bitumen under current exposure conditions in humans remained limited.

This situation led to the initiation of a new occupational study in mastic asphalt workers exposed to vapors and aerosols of bitumen under current exposure conditions. The principal aim of this large-scale Human Bitumen Study in Germany was to assess irritative effects of vapors and aerosols on the airways, using a cross-shift design in a wellcharacterized group of bitumen-exposed workers. Furthermore, it appeared worthwhile to use the study to determine possible genotoxic effects in blood cells. With the examination of 500 workers, the new Human Bitumen Study is one of the largest investigations of bitumen-exposed workers under current working conditions. The results of these studies are important, if new OELs will be considered.

The project is an example of successful collaboration of different disciplines, namely occupational hygienists and physicians, pneumologists, immunologists, epidemiologists, and toxicologists. In this supplemental issue of 
"Archives of Toxicology", the study results are presented in a comprehensive form.

\section{References}

Fuhst R, Creutzenberg O, Ernst H, Hansen T, Pohlmann G, Preiss A, Rittinghausen S (2007) 24 months inhalation carcinogenicity study of bitumen fumes in wistar (WU) rats. J Occup Environ Hygiene 4:20-43
Greim H (ed) (2001) Gesundheitsschädliche Arbeitsstoffe. Bitumen (Dampf und Aerosol).Toxikologisch-arbeitsmedizinische Begründungen von MAK-Werten. Lfg, Weinheim: Wiley-VCH, p 32

Sivak A, Niemeier R, Lynch D, Beltis K, Simon S, Salomon R, Latta R, Belinky B, Menzies K, Lunsford A, Cooper C, Ross A, Bruner R (1997) Skin carcinogenicity of condensed asphalt roofing fumes and their fractions following dermal application to mice. Cancer Lett 117:113-123 